\title{
Informational cognitive model applied to the water resources management
}

\author{
L. G. Baganha Jr ${ }^{1}$, A. R. Baganha Barp ${ }^{1} \&$ W. J. Barp ${ }^{2}$ \\ ${ }^{1}$ Program of Pos-Graduation in Civil Engineering, \\ Federal University of Para, Brazil \\ ${ }^{2}$ Program of Pos-Graduation in Social Sciences, \\ Federal University of Para, Brazil
}

\begin{abstract}
Tucunduba's basin in Brazil was chosen for the area of research into the development of a cognitive computational causal structure that was capable of identifying and qualifying the potential conflict processes generated from the multiple uses of the water in this urban basin, and to use the information in making decisions as to the possible scope of structural and non-structural actions.
\end{abstract}

The use of a qualitative model in the area of water resources, using informational methodologies like the software Decision Explorer, aims not only to understand the water aspects, but also the social and indispensable aspects in taking a decision in a conflict scenario regarding the use of these resources. This software is a tool for the development of the cognitive mapping, where concept gathering representative causes and effects will be joined through a coded visualization.

The conflicting identification and qualification caused by the multiple uses of the water has been carried out through interviews with specialists in the area of management and sanitation. This information was added to a map with the purpose of proving the hypothesis formulated in the research, through the use of analysis tools to assist the problem identification due to the multiple use of the water, from existing structural and non-structural measures (or proposals), in order to provide the manager with more effective solutions to solve these problems. It can be said that this group of items illustrate the main measures to be observed by the manager, in order to solve the conflicts for the multiple use of the basin, highlighted by the interviews and individual cognitive maps.

The conclusions reached were mainly by means of the researcher's intervention and interpretation of the data and based on these analyses an understanding of the systems is obtained, potential conflicts identified with their causes and effects, and suggestions for mitigating measures proposed.

Keywords: cognitive model, conflicts for the use of the water, informational methodology, decision analysis, water management resources, decision explorer. 


\section{Introduction}

The research was carried out in the Tucunduba's basin, in Belém's, state of Pará, Brazil, urban zone and aims to develop a cognitive computational causal structure capable of identifying and qualifying the potential conflicts processes generated from the multiple uses of the water in this urban basin, and with this to make decisions possible in the scope of structural and not structural actions

The use of a qualitative model in the area of water resources, using informational methodologies like the software Decision Explorer, aims not only to understand the hydro aspects, but also the social, indispensable aspects in taking decision in a conflict scenario regarding the use of these resources. This software is a tool for the development of the cognitive mapping, where concepts gathering of representative causes and effects will be joined through a coded visualization.

The conflicts' identification and qualification caused by the multiple uses of the water has been carried out through interviews with specialists in the area of management and sanitation. Later, cognitive maps were generated making possible the system description and the identification of possible solutions to the problems found there. The information from the interviews was added to a map with the purpose of proving the hypothesis formulated in the research through the use of analysis tools to assist the identification of problems due to the multiple use of the water from existing structural and not structural measures (or proposals), in order to provide the manager with more effective solutions to solve these problems. It can be said that this group of items illustrate the main measures to be observed by the manager in order to solve the conflicts for the multiple use in Tucunduba's basin, highlighted by the interviews and individual cognitive maps.

The conclusions and suggestions are taken not only through the extracted results of the software used, but mainly by means of the researcher's intervention and interpretation of the data, and based on these analyses can get the system's understanding, the potential identification of conflicts, its causes and effects, as well the mitigating measures to be suggested to the management.

\section{Study area: Tucunduba basin}

Tucunduba's basin, fig. 1, in one of the right edge Guamá River tributaries, is located in Southeast Belém, in the state of Pará. Belém and is one of the metropolises of Brazil and also the greater and more developed city of the country's North Region, located in the vertex of an estuary, in a point of junction of the maritime and fluvial influences, crossed by innumerable water streams that cut across the region. The City is composed of 43 islands, with a territory of approximately $1,065 \mathrm{~km}^{2}$ and, despite the rivers and "igarapés" are part of the city. The city's urbanization process caused innumerable forms of aggression to the water resources of the region. The use of the urban rivers as a final destination of waste causes landfilling and worse. 


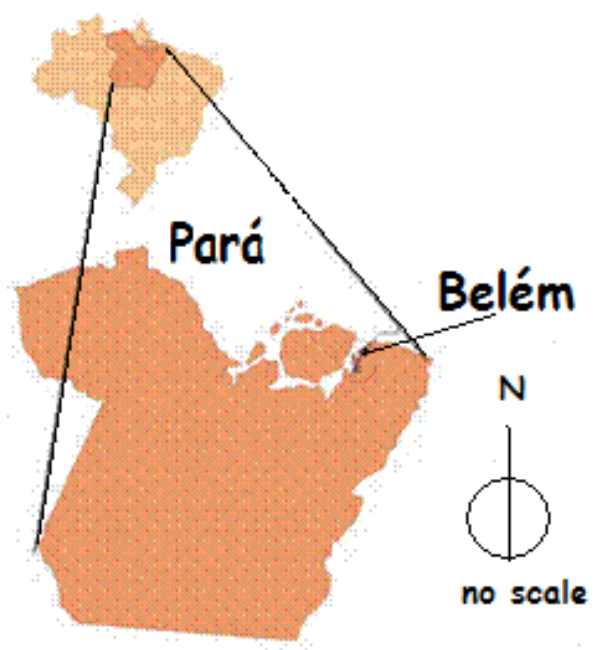

Figure 1: Belém's location, in Brazil.

The city has been facing an intense urbanization process with a fast growing population increase totalling about $1,279,861$ inhabitants, according to a general consensus of the population in 2000 [7]. Belém's area has around 1,8 million inhabitants. This population is basically located in the urban area $(99,53 \%)$, indicating a higher urbanization rate compared to the state's and Amazon's rate. The population rate is $1,201,39 \mathrm{inh} / \mathrm{km}^{2}$

\section{Informational methodology}

The term informational methodology is used in social, computational and hydro sciences, to assign instruments and techniques that are formed by theories materialized by methodological tools that can amplify and modify cognitive human functions like: memory, hyper documents, data bases, digital files, imagination, perception and complex phenomena modelling [4].

The objective of the use of the qualitative model through the application of informational methodology in the area of water resources is to understand the aspects of public and social politics, and not only the hydrographic basin hydro aspects which are indispensable in formulating decisions concerning the multiple uses of these resources. Based on this context, this work shows computational program using techniques and tools to assist in the decision taking process through the qualitative modelling of the processes that indicate multiple uses of current conflicts, making the description of existing structural and not-structural measures possible and, consequently, indicating possible mediating solutions for the conflicts identified there.

The qualitative software Decision Explorer was used to make this procedure and its interrelation possible. It has the benefit to express through the cost and 
time saving, the possibility to explore in an accurate way the relationship between the data, and on the other hand, the advantages in terms of a formal structure that assists in the conceptual and theoretical construction of the data. Thus, the analysis of the bibliographical material and the interviews can be built through established codification for the defined categories such as: probable existing conflicts - conflict of use destination, conflict of qualitative availability, conflict of quantitative availability.

\subsection{Qualitative data structuring mapping methods (QDS)}

There are four different methods of mapping knowledge: mental mapping (Mind Mapping), developed initially by Tony Buzan [2]; conceptual mapping (Conceptual Mapping [6]), developed by Joseph Novak; cognitive mapping (Cognitive Mapping), idealized by Colin Eden - with David Sims and Sue Jones and later with Fran Ackermann [5], and colloquial mapping (Dialog Mapping), developed by Jeff Conklin [3]. Each of these methods supplies a structure of qualitative data (ideas) and has distinct characteristics. Any one of these methods can be interesting and useful for individuals and groups of investigators that need to structuralize a proper way of thinking in a project or desire to use one of the methods to get new introspections in research data.

Although of different origins, these four mapping ideas (QDS) are generic methods and can all be used in the study field [1]. In addition, a common point through the use of all the methods and their use in understanding and in the construction consensus inside the groups, as well their use as tools to think and to learn individually. They can be used as "learning tools": they help researchers to explore and to define what they are trying to make - structuralizing the proper way of thinking during the project (from sketching the project, to structuralize the final report) or as "exploratory tools": they help researchers to build a visual representation of the interview or perceptions of the group.

The cognitive mapping is defined as a composed process of a series of psychological transformations, which an individual acquires, codifies, stores and decodes information about localizations and the relative attributes to the phenomena in its daily environment.

The cognitive mapping method is an example of the narrow relationship between the process of primary elements briefing evaluation and the model's structure, where from determined initial facts raised the facilitator questions the ones who are in charge of decision or the actors involved in the system dynamics to the degree importance of facts, proceeding with this type of questioning to get a chain of linked factors that will compose the clusters, that are interest areas, to the point where the decider establishes that such a factor is complete, (fig. 2). This process, without a doubt, contributes in a decisive way to the problem's understanding and to the characteristics identification of the actions, through which the actors value the main purpose [9]. Usually, it is difficult for the facilitator to identify clearly the role of subjective and objective elements. 


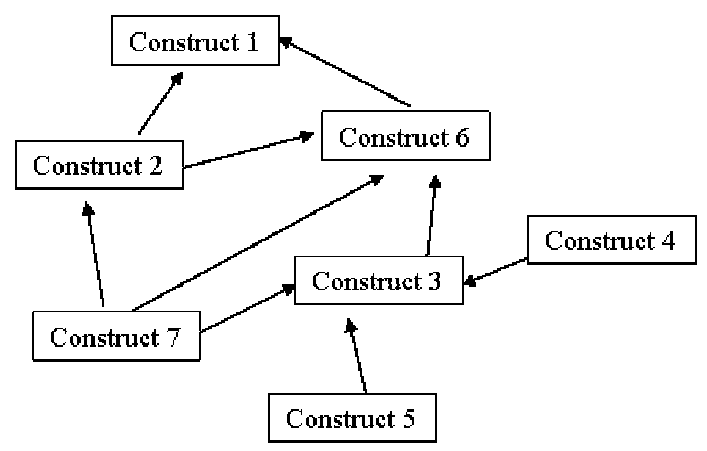

Figure 2: Cognitive map.

\section{Cognitive mapping process}

As a mapping starting point, an interview agenda with professionals of recognized knowledge in management and urban infrastructure services was established, with the intention of identify from its point of view, the main existing conflicts in an urban hydrographic basin, with emphasis in the Riacho Doce area and the Tucunduba basin which is the study site of the present work, with its causes, effects and possible solutions. Following with the mapping process, the maps generated from the interviews were grouped (figs 3-5)

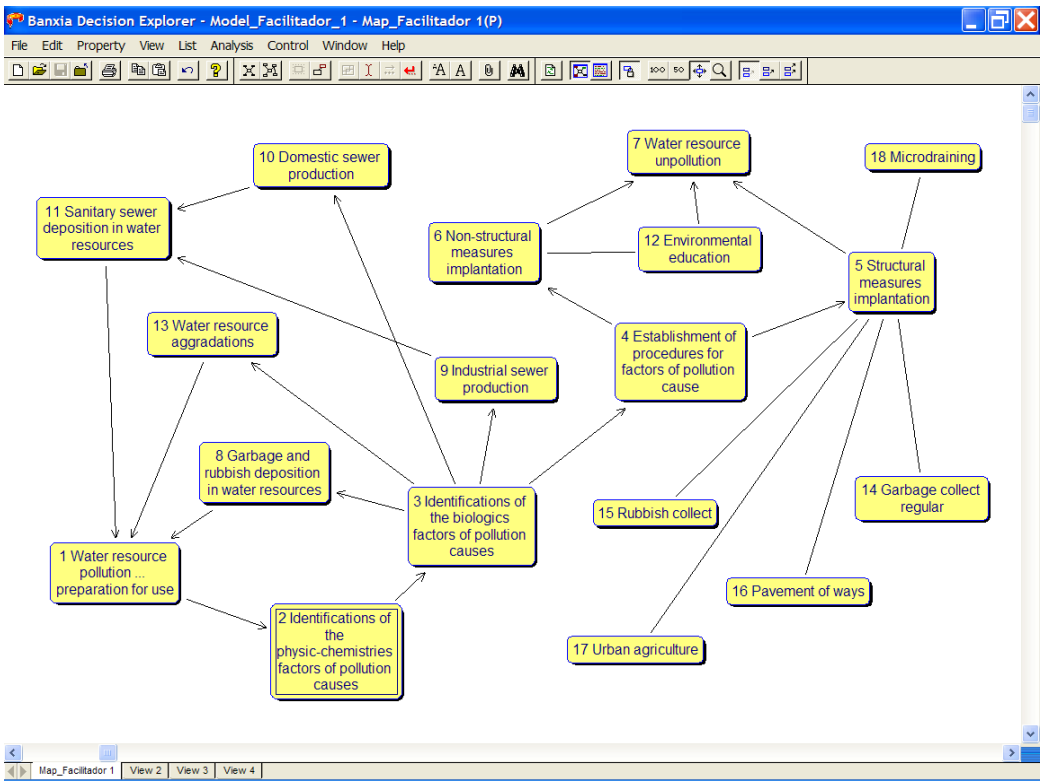

Figure 3: Facilitator 1 cognitive map. 


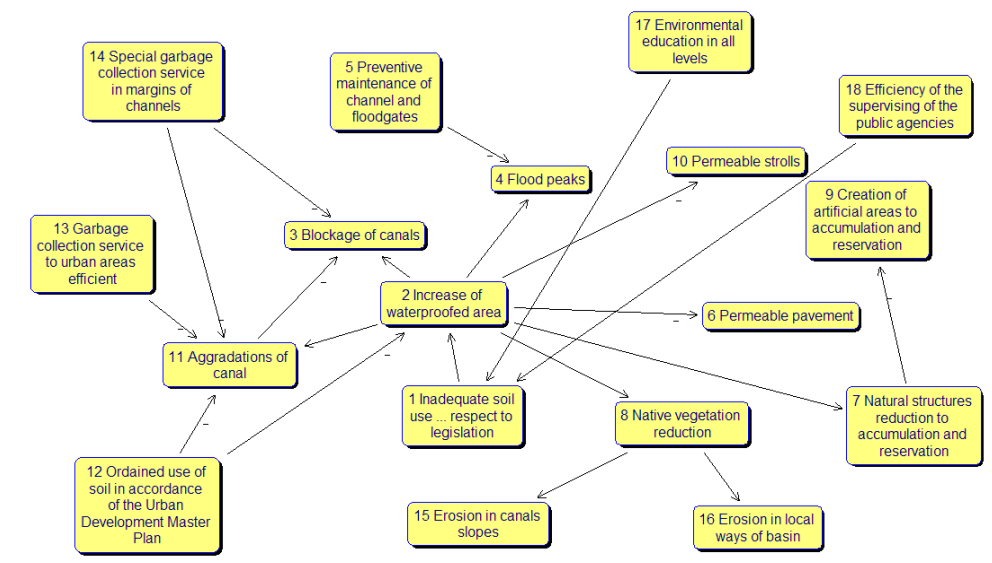

Figure 4: Facilitator 2 cognitive map.

Banxia Decision Explorer - Model_Facilitador_3 - Facilitador 3(P)

Eile Edit Property Wiew List Analysis Control Window Help

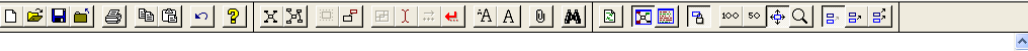

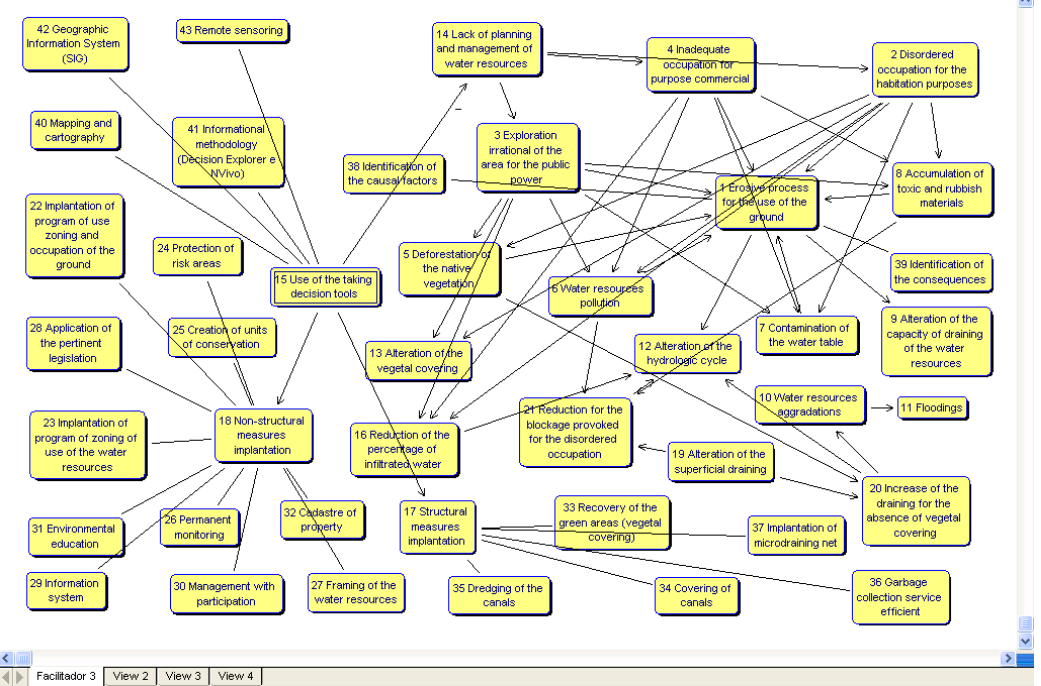

Figure 5: Facilitator 3 cognitive map.

Initially, Facilitators 2 and 3 maps were joined, keeping the corresponding construct and links. The choice was made because of the fact that these two 
interviews generated the biggest maps, and therefore a higher degree of difficulty in the association between similar concepts. In this phase, the category of the constructs (concepts) generated by the facilitators was also defined, based on its own characteristics, related to the environmental factors established in the General Outlines to evaluate Environmental Impacts defined in Resolution $n^{\circ} 01$, of National Council of Environment (CONAMA), January 23, 1986. The Facilitator 1 map was added later.

The cognitive map added through Model Cognitive Informational of Support to the Decision (CISDE) is the result of the set obtained from joining the constructs generated in individual facilitator's maps. This map was created with the intention to test the hypothesis formulated in the research by means of the tool analysis, or, to assist the identification of the multiple use of the water conflicts from existing structural and not structural measures (or proposals) observed, in order to provide the manager with a more efficient solution to solve these problems.

The subsequent analyses were carried through the commands LOOP, CLUSTER and HIESET and POTENCY (or POTENT). These commands, tools of program analysis, generate specific sets of constructs from the general map aggregated, which has the purpose to evaluate the map by means of the hierarchic structure chaining and its linking, known as "Tear-drops", that are composed by all the elements that support or explain the main construct of the set.

Through these analysis tools it was possible to extract the more meaningful constructs as a cause of conflicts identified from the general map. A group of constructs having the largest number of hierarchic sets ("tear-drops") associated to them was obtained from POTENT tool (table 1).

In this construct's group, only n $\mathrm{n}^{\mathrm{O}} 15$ ("Use of aid tools to decision taking") is a potential events generator construct. The others are identified as indicators, working only as explanation support for associated constructs in the arguments chain. Construct $\mathrm{n}^{\mathbf{0}} 15$, identified as being a concept TAIL, is, because of this, a potential generator of events, or it helps to support the goals to be reached (in a positive or negative way) in the mapping. The map generated from CONSEQUENCES analyses (fig. 6), highlights the chain of events generated from construct $\mathrm{n}^{\mathrm{o}} 15$.

Table 1: $\quad$ Constructs belonging to 5 (five) hierarchic sets.

\begin{tabular}{|ll|}
\hline Set & \\
\hline 15 & Taking Decision Tools \\
\hline 40 & Mapping and Cartography \\
\hline 41 & Informational Methodology (Decision Explorer e NVivo) \\
\hline 42 & Geographic Information System (SIG) \\
\hline 43 & Remote Sensoring \\
\hline
\end{tabular}




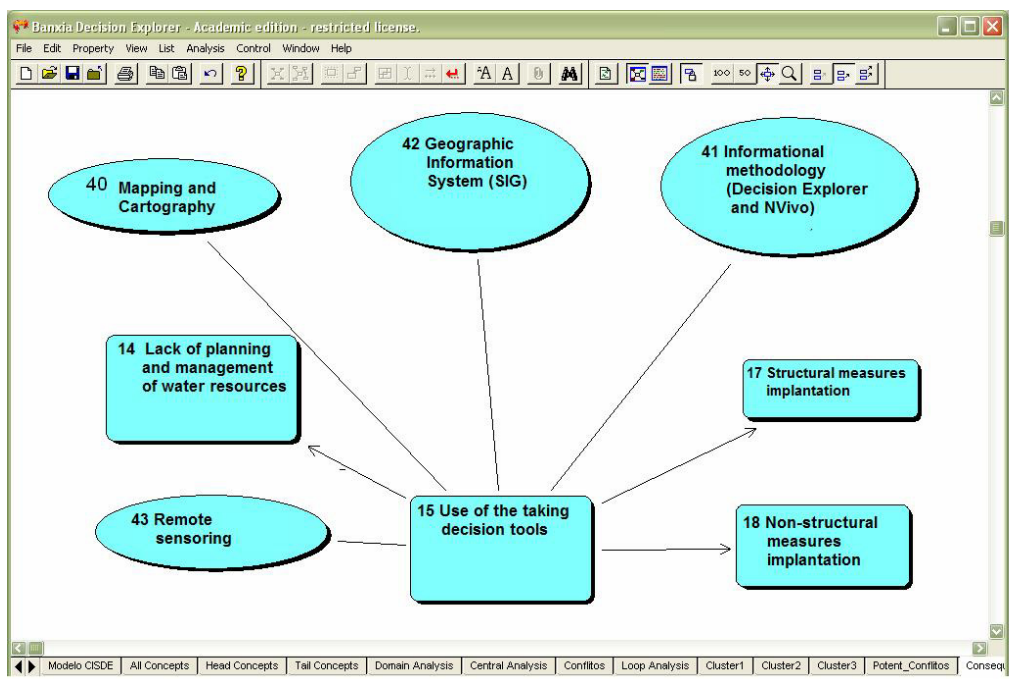

Figure 6: Consequences analyses map - concept 15 .

\section{Conclusion}

The use employing decision tools such as the informational methodology and Decision Explorer in this research also provided the identification of the existing types of conflict in the study area and also the alternatives in aiming for the mediation for its solution, assuring the research hypothesis. It is important to emphasize the importance of data interpretation and cognitive mapping that lead the researcher to reach the results, not only in the software results extracted. There was a concern in not interpreting them as static representations of the studied system - the process of mapping by CISDE allows a permanent update, monitored by the manager, taking into account the experience acquired during the events.

The CISDE model used in this study was able to identify the following potentialities:

- improve the group intelligence through public management related to hydrographic basin and later to all individuals related;

- establish a public management view;

- $\quad$ add to group concepts;

- enable and make theory construction easy because everyone needs a theory;

- enable the study of subsystems, and

- enable the observation through a point of multiple criteria and abstraction.

These aspects lead us to conclude that the modelling, through this methodology presents some advantages such as: to construct models and to generate simulation when the available data is still incomplete; to construct 
models by reusing parts of other models or from the combination of simpler models to represent more complex problems; to provide the manager with some observed scenarios, as well as foreseeing future scenarios, aiming for more flexible results, and representing in an explicit way the causality between the elements of the model that makes possible the support of the explanations on the behaviour of the system from its structure.

\section{References}

[1] Brightman, J. Mapping methods for qualitative data structuring (QDS). Online. www.banxia.com.

[2] Buzan, T. Mind Mapping. Online. www.mind-map.com/EN/mindmaps/ definition.html.

[3] Cognexus Institute. Dialog Mapping. Online. www.cognexus.org/ id17.htm.

[4] Costa, A. P. Metodologia multicritérios em apoio à decisão para solução de cultivares de arroz para lavouras no sul do Estado do Rio Grande do Sul. Online. www.eps.ufsc.br/disserta96/costa/index.

[5] Eden. C. and Ackermann, F. Making strategy: the journey of strategic management. Sage Publications: London, 2002.

[6] Isaacs, J. Concept-mapping software: how effective is the learning tool in an online learning environment? Online. edcompass.smarttech.com/ en/learning/research/pdf/ConceptMapsOnlineLearningEnvironment.pdf.

[7] Prefeitura Municipal de Belém (PMB). Plano de Desenvolvimento Local Riacho Doce e Pantanal. SEGEP: Belém. 2001. CD ROM.

[8] Tavares dos Santos, J. V. As possibilidades das metodologias informacionais nas práticas sociológicas: por um novo padrão de trabalho para os sociólogos do século XXI. Sociologias: metodologias informacionais, org. Tavares dos Santos, J. V. UFRGS/IFCH: Porto Alegre, pp. 116-148, 2001. 